\section{Nueva meta de los programas de vacunación en la Región de las Américas: eliminar la rubéola y el síndrome de rubéola congénita ${ }^{1}$}

Palabras clave: rubéola, síndrome de rubéola congénita, vacunación, Américas.

\footnotetext{
Basado en el documento Mantenimiento de los programas de vacunación - eliminación de la rubéola y del síndrome de rubéola congénita, presentado en la 44. ${ }^{\circ}$ Consejo Directivo, Organización Panamericana de la Salud, Washington, D.C., EUA, del 22 al 26 de septiembre de 2003. (Documento CD44/11). Disponible en: http://www.paho.org/ english/gov/cd/cd44-11-s.pdf (acceso el 17 de octubre de 2003).
}

Durante los debates de su 132. a sesión en junio de 2003, el Comité Ejecutivo de la Organización Panamericana de la Salud (OPS) solicitó a los Estados Miembros que elaboraran en el plazo de un año planes de acción nacionales orientados a eliminar la rubéola y el síndrome de rubéola congénita (SRC) del territorio americano para el año 2010.

En los últimos 25 años se han alcanzado metas importantes en la lucha contra las enfermedades infecciosas prevenibles por vacunación. En la Región de las Américas ha habido adelantos muy notables. No solo se ha reducido la transmisión autóctona de muchas de estas enfermedades, sino que también se ha conseguido, entre otras cosas, que la cobertura y calidad de la vacunación sea uniforme en todos los municipios del territorio. Gracias a los buenos resultados de los programas de vacunación en la Región, la inmunización se ha convertido en uno de los pilares del programa mundial para lograr el crecimiento económico sostenible y la reducción de la pobreza.

A medida que se ha reducido la incidencia de algunas enfermedades prevenibles por vacunación, tales como la poliomielitis y el sarampión, el interés de la comunidad sanitaria en la Región se ha volcado hacia combatir la rubéola y el SRC. El descubrimiento del efecto teratógeno del virus de la rubéola en 1942 por el oftalmólogo australiano Norman Gregg atrajo hacia esta enfermedad una atención que antes no suscitaba. Cada año nacen en el mundo decenas de miles de niños con anomalías congénitas debido a que sus madres contrajeron rubéola durante el embarazo. En muchos casos, la contracción de la rubéola durante la gestación lleva a un aborto espontáneo o a la necesidad de un aborto terapéutico. El SCR se caracteriza por bajo peso al nacer y por anomalías graves, tales como sordera, ceguera y malformaciones cardiovasculares. En ocasiones sobreviene la muerte prematura.

Antecedentes de los programas de vacunación nacionales

La factibilidad de erradicar la rubéola y el SRC para el año 2010 está fundamentada en los buenos resultados que han dado las campañas de vacunación anteriores. En primer lugar, el Programa Ampliado de Inmunización (PAI) de las Américas — que celebró su $25 .^{\circ}$ aniversario en 2002 - es una 
de las intervenciones de salud que ha dado mejores resultados en el terreno de la salud pública. Su éxito se ha atribuido principalmente al compromiso de los Estados Miembros con el establecimiento de programas nacionales de vacunación y con la prestación del apoyo técnico y político necesario para lograr el mejor rendimiento posible.

Gracias a la colaboración entre la OPS y sus Estados Miembros, la Región presenta actualmente las tasas más bajas del mundo de morbilidad y mortalidad a causa de enfermedades prevenibles por vacunación. La OPS y los Estados Miembros han creado redes extensas, de alcance nacional y regional, para la inmunización contra las enfermedades prevenibles por vacunación y para la vigilancia de estas enfermedades. El establecimiento de redes de cooperación en torno a las enfermedades prevenibles por vacunación sigue siendo una de las principales estrategias de la OPS para impulsar las iniciativas de los países en este ámbito y aprovechar los recursos de información y tecnología que tiene la Región. Asimismo, los alentadores resultados alcanzados por los programas nacionales de vacunación han sentado los cimientos sobre los cuales se puede erigir una campaña para erradicar la rubéola y el SRC (cuadro 1).

Las redes establecidas inicialmente para combatir la poliomielitis y el sarampión han sido adaptadas a la vigilancia de la meningitis bacteriana, la neumonía, el SRC y la infección por rotavirus. Estas redes han ayudado a los países a generar datos de morbilidad que les permiten a las autoridades sanitarias definir prioridades en cuanto a la introducción de vacunas nuevas o subutilizadas, determinar el costo de otras opciones preventivas y medir los efectos de la vacunación (cuadro 2).
En aras de lograr una mayor equidad, los programas nacionales de vacunación se han fijado la meta de alcanzar una cobertura uniforme en todos los municipios, haciendo hincapié en mejorar la supervisión, la seguridad de la vacunación y la gerencia de los recursos financieros y humanos, así como la fiabilidad de los datos de vacunación recabados, analizados y notificados a la instancia central. Los planes de acción establecidos en 1983, tanto nacionales como locales, siguen siendo el principal instrumento utilizado por la OPS para lograr cambios en aquellos distritos cuyo desempeño es bajo. La OPS y los Estados Miembros han instaurado la Semana de Vacunación en las Américas, que se celebra cada año, para promover la vacunación de grupos de población en alto riesgo y de habitantes de zonas menos atendidas.

\section{Retos y dificultades de los programas de vacunación}

Los objetivos de los programas de inmunización forman parte de las metas de desarrollo del milenio - respaldadas por todos los miembros de las Naciones Unidas - y de las estrategias de reducción de la pobreza fijadas por las instituciones financieras internacionales. No obstante, la crisis económica imperante en la mayoría de los países de la Región constituye el mayor obstáculo para lograr que los programas rindan los resultados deseados. Las fluctuaciones en la asignación de los recursos, resultado de estos problemas económicos, así como la gestión desigual de la reforma sanitaria y de los procesos de descentralización, están poniendo en peligro la ejecución de los programas nacionales de

CUADRO 1. Adelantos logrados hasta octubre de 2003 por los programas nacionales de vacunación

\begin{tabular}{ll}
\hline \multicolumn{1}{c}{ Enfermedad } & \multicolumn{1}{c}{ Resultado } \\
\hline $\begin{array}{l}\text { Poliomielitis } \\
\text { Sarampión }\end{array}$ & $\begin{array}{c}\text { Está erradicada la circulación del virus salvaje desde } 1991 . \\
\text { La interrupción de la transmisión autóctona está a punto de lograrse en todo el } \\
\text { continente americano. }\end{array}$ \\
$\begin{array}{l}\text { Tétanos neonatal } \\
\text { La enfermedad se limita a menos de } 1 \% \text { de los distritos del territorio americano. }\end{array}$ \\
$\begin{array}{l}\text { Fiebre amarilla selvática } \\
\text { Heumonía y meningitis bacterianas }\end{array}$ \\
$\begin{array}{l}\text { Sague ampliándose la red de hospitales centinelas vinculados a laboratorios de salud } \\
\text { pública y a unidades epidemiológicas. }\end{array}$ \\
$\begin{array}{l}\text { Hepatitis B, infección por Haemophilus } \\
\text { influenzae tipo b, sarampión, parotiditis } \\
\text { y rubéola }\end{array}$ & $\begin{array}{l}\text { Se adoptó la incorporación generalizada de la vacuna multivalente. } \\
\text { Fiebre amarilla }\end{array}$ \\
\hline
\end{tabular}




\section{CUADRO 2. Hitos de la colaboración internacional en materia de vacunas e inmunización en las Américas, 1977-2002}

1977 Una resolución del Consejo Directivo de la OPS establece el Programa Ampliado de Inmunización (PAl) en las Américas. Otra resolución establece el Fondo Rotatorio para la Adquisición de Vacunas de la OPS.

1978 Todos los países nombran un gerente para su programa nacional de inmunización. La OPS inicia cursos de capacitación para gerentes del PAI.

1979 La Conferencia Sanitaria Panamericana autoriza la capitalización del Fondo Rotatorio. Se adquieren vacunas por US\$2,5 millones mediante el Fondo Rotatorio. Se publica el primer ejemplar del Boletín Informativo PAI.

1980 La OPS desarrolla una metodología para la evaluación/revisión multidisciplinaria de los programas nacionales de inmunización.

1981 La publicación científica de la OPS titulada Inmunización y la salud primaria: problemas y soluciones, da pauta para la cooperación técnica en el PAI.

Se celebran la primera reunión subregional de gerentes del PAI y el primer curso sobre la cadena de frío en Ecuador.

La OPS publica un documento sobre la entrega de servicios de inmunización, en el que se resume el papel de la combinación de enfoques verticales y horizontales aplicados en los programas de inmunización.

1983 Los países comienzan a crear planes, más tarde conocidos como Planes Nacionales de Acción, como herramienta para mejorar el desempeño de los programas de inmunización.

La Región de las Américas fue la primera en idear y celebrar los Días de Tranquilidad para llevar a cabo las campañas de inmunización en áreas en conflicto en América Central, concepto que ahora se ha diseminado mundialmente.

1985 La OPS declara la meta de erradicar la polio del hemisferio occidental para el año 1990.

El Director de la OPS nombra el Grupo Técnico Asesor del PAI.

Se establece el Comité de Coordinación Interagencias (CCl) de la OPS, con la participación de la Agencia de los Estados Unidos para el Desarrollo Internacional (USAID), el Fondo de las Naciones Unidas para la Infancia (UNICEF), el Banco Interamericano de Desarrollo (BID) y el Club Rotario Internacional, así como representantes de los distintos Estados Miembros.

A partir de los Planes Nacionales de Acción para mejorar el desempeño de los programas de vacunación, los países de la Región generan el primer ciclo de Planes de Acción quinquenales (1986-1990) basado en la identificación de necesidades de recursos de fuentes tanto nacionales como internacionales.

1986 Se acelera el control del tétanos neonatal en la Región.

Se obtienen US\$110 millones de los miembros del Comité de Coordinación Interagencias.

1987 Conforme a la recomendación de la OPS, Cuba lanza la primera campaña de erradicación de sarampión en la Región.

1991 Se notifica en el Perú el último caso autóctono de polio.

Se obtienen US\$ 60 millones de miembros del Comité de Coordinación Interagencias.

1994 La Región de las Américas se certifica libre de polio.

Se establece la meta de erradicar el sarampión.

1995 Se crea el Programa Especial de Vacunas e Inmunización de la OPS.

1996 Se acelera la introducción de nuevas vacunas (contra el sarampión, la parotiditis y la rubéola; la hepatitis B; y Haemophilus influenzae tipo b).

Se obtienen US\$ 32 millones de los miembros del Comité de Coordinación Interagencias.

1999 La OPS establece la División de Vacunas e Inmunización.

Se adquieren US\$ 85 millones en vacunas por conducto del Fondo Rotatorio.

Se suscriben al Comité de Coordinación Interagencias los Centros para el Control y la Prevención de Enfermedades (CDC), el Banco Mundial y March of Dimes.

2001 Se adquieren vacunas por más de US\$ 100 millones mediante el Fondo Rotatorio.

Se inicia el cuarto ciclo de Planes de Acción quinquenales (2001-2005) para mejorar el desempeño de los programas de vacunación.

Conforme a resoluciones de la OPS, los Estados Miembros inician el control acelerado de la rubéola y del síndrome de rubéola congénita.

2002 Se obtienen US\$ 7,6 millones del Fondo Rotatorio.

La capitalización del Fondo Rotatorio alcanza US\$ 23 millones.

Una resolución de la OPS subraya la importancia de la rendición de cuentas y la sostenibilidad de los programas nacionales de inmunización.

Fuente: Basado en: Organización Panamericana de la Salud. Vacunas e Inmunización en las Américas: hitos 1977-2002. Boletín Informativo PAl 2002;24(6). Se encuentra en: http://www.paho.org/spanish/hvp/hvi/sns2406.pdf. Acceso el 18 de octubre de 2003. 
vacunación. Ello implica que si se produce un brote de alguna enfermedad prevenible por vacunación, los costos para el sector sanitario indudablemente aumentarán.

Ante el reto planteado por las disparidades que aún existen en materia de inmunización, los Estados Miembros se proponen reducir las diferencias en el acceso a la vacunación, que siguen socavando el principio de la equidad en el que se fundamentan los programas de inmunización. Las iniciativas en este sentido resultan difíciles de aplicar debido, como ya se ha señalado, a la grave crisis económica que sufren los países de la Región de las Américas, que se produce precisamente mientras los países buscan introducir vacunas nuevas en sus calendarios sistemáticos de vacunación, con un consiguiente aumento del costo, por niño vacunado, de los servicios de vacunación sistemática, aun con las vacunas básicas del PAI. A las consecuencias de la crisis económica se suman los efectos de los cambios en la dirección y ejecución de los programas nacionales de salud derivados de la reforma sanitaria y la descentralización. Estos cambios en los sistemas sanitarios obstaculizan la ejecución eficaz y uniforme de los programas nacionales de vacunación. Las fluctuaciones en la asignación de los recursos - ocasionadas por la crisis económica y por las desigualdades de la reforma y la descentralización-constituyen otro obstáculo que pone en peligro los programas nacionales de vacunación. Como ya se ha dicho, esta situación podría aumentar los costos para la sociedad si llegase a producirse un brote de alguna enfermedad prevenible por vacunación.

A fin de proteger los logros que se han alcanzado en el campo de la salud pública y los efectos favorables que han tenido los programas nacionales de vacunación, así como para garantizar que los programas se sigan ampliando, los Estados Miembros y la comunidad internacional deberán iniciar un diálogo encaminado a estudiar qué medidas sostenibles podrían proteger las inversiones realizadas en materia de vacunación y garantizar un flujo constante de vacunas para los Estados Miembros a un costo asequible. Para lograr estas metas es necesario dar los siguientes pasos:

- Garantizar los recursos que permitan continuar las estrategias establecidas. Los sectores financieros y los ministerios de finanzas de los Estados Miembros deben estar atentos a las posibles consecuencias adversas de interrumpir los programas de vacunación. El logro de mecanismos de financiamiento seguros para estos programas a escala nacional debe regirse por criterios de equidad.

- Fortalecer la capacidad de gestión, el conocimiento de los objetivos de vacunación y el com- promiso con estos objetivos a escala municipal y local, de modo que los gerentes locales de los programas de inmunización procedan a asignar recursos adecuadamente. Para garantizar el cumplimiento de las metas y mejorar la calidad del trabajo, la supervisión educativa habitual se deberá presupuestar y poner en práctica en todos los países.

- Elaborar e implementar estrategias de información, educación y comunicación con miras a mejorar los conocimientos de la comunidad en cuanto a los beneficios de la vacunación, y a fomentar la demanda de tales servicios, especialmente por grupos de población en alto riesgo. Un ejemplo es el de la Semana de Vacunación en las Américas, iniciativa anual emprendida recientemente en los países de la Región para promover la vacunación en las zonas menos atendidas y donde es alto el riesgo de infección.

- Fortalecer el diálogo de los Estados Miembros con la comunidad internacional acerca del financiamiento de la vacunación, procurando crear nuevos mecanismos financieros para respaldar las iniciativas de alcance internacional. Por tratarse de un problema regional e internacional, con externalidades fronterizas importantes, es necesario subrayar que los programas de vacunación son un bien público y que requieren de insumos y medidas más allá de los límites y las jurisdicciones nacionales.

Lograr la sostenibilidad y el desarrollo de los planes nacionales de vacunación contra las enfermedades prevenibles mediante vacunas es una responsabilidad tanto de las autoridades sanitarias nacionales como de toda la comunidad internacional.

\section{La eliminación de la rubéola y del SRC para el año 2010}

En ocasión de la reunión de 1999 del Grupo Técnico Asesor de la OPS sobre Enfermedades Prevenibles por Vacunación se formuló una estrategia acelerada para el control de la rubéola y la prevención del SRC en las Américas, tomando en cuenta la experiencia adquirida en las campañas para la vacunación antirrubeólica masiva en el Caribe de habla inglesa y Cuba. El elemento fundamental era la vacunación de hombres y mujeres adultos, complementada por la introducción de la vacuna antirrubeólica en los programas nacionales de vacunación infantil. Mediante esta estrategia combinada de vacunación se pretendía lograr la reducción rápida de la circulación del virus de la rubéola y evitar al mismo tiempo que la carga de morbilidad se desplazara a los adultos jóvenes susceptibles, en 
particular a las mujeres en edad fecunda. De esta manera se buscaba disminuir la incidencia del SRC.

El objetivo de la estrategia acelerada de vacunación antirrubeólica es interrumpir la circulación del virus de la rubéola y prevenir la aparición del SRC. En la mayoría de los países de la Región, la vacunación infantil contra la rubéola es una práctica habitual destinada a proteger a los niños que alcanzan a cumplir un año de vida. No obstante, podría tomar más de veinte años controlar el SRC, pues varias cohortes de mujeres en edad fértil seguirían siendo susceptibles al virus de la rubéola.

Varios países han emprendido medidas para el control acelerado de la rubéola y la prevención del SRC. La implantación continua de estrategias fructíferas y sostenibles de vacunación de adultos con una cobertura mínima de $90 \%$ ha aportado enseñanzas y conocimientos importantes. Se ha adquirido experiencia con la vacunación antirrubeólica masiva de hombres, mujeres y adolescentes en Costa Rica, Honduras, Brasil y los países del Caribe de habla inglesa, cuya experiencia también ha proporcionado datos útiles en cuanto a la relación entre los costos y beneficios de la vacunación contra la rubéola.

El análisis de las experiencias mencionadas indica que los beneficios del control acelerado de la rubéola mediante la vacunación exceden ampliamente los costos asociados con el tratamiento y la rehabilitación de niños con el SRC. La relación entre los costos y beneficios de la interrupción de la rubéola y la prevención del SRC en todo el Caribe de habla inglesa se calculó en 1:13,3. Asimismo, por caso de SRC evitado se produce un ahorro promedio de US\$ 2 900,00 gracias a estas campañas de vacunación en masa. Tras haber interrumpido la transmisión, Barbados obtuvo una razón entre costos y beneficios de 1:4,7 y Guyana, de 1:38,8. Cada caso de SRC evitado representó un ahorro de US\$ 1 633,00.

En un plazo breve, las estrategias aceleradas de vacunación antirrubeólica han reducido la morbilidad por SRC registrada en Cuba, el Caribe de habla inglesa y Chile y han interrumpido la transmisión del virus de la rubéola en Costa Rica. Actualmente se reconoce que el SRC es un grave problema de salud pública, pero la vigilancia sigue arrojando datos alarmantemente escasos que solo brindan una visión incompleta de la carga real de morbilidad y de los resultados de las iniciativas antirrubeólicas. Frente a esta situación, se están aplicando instrumentos suplementarios que pueden mejorar la identificación de los casos de SRC.

La mayor atención que se presta actualmente al control de la rubéola y del SRC en las Américas ya ha reportado beneficios. Es evidente el rápido aumento del número de países y territorios que notifican los casos de rubéola, factor que ha permitido mejorar el análisis de la morbilidad correspondiente. Además, este aumento de la atención ha propiciado una mayor integración de los sistemas de vigilancia de la rubéola y el sarampión en la Región, así como un mejoramiento de la sensibilidad y especificidad de los métodos usados para el diagnóstico de la rubéola.

La rápida reducción de la morbilidad gracias a la estrategia acelerada del control de la rubéola - unida a la existencia de una vacuna segura, asequible y eficaz, a la demostrada rentabilidad de vacunar contra la rubéola y al amplio apoyo proporcionado por la población y las autoridades sanitarias de los Estados Miembros- ha preparado las condiciones que permiten establecer la meta de eliminar la rubéola y el SRC de las Américas para el año 2010.

\section{SYNOPSIS}

\section{New goal for vaccination programs in the Region of the Americas: to eliminate rubella and congenital rubella syndrome}

The vaccination programs of the countries in the Region of the Americas have produced notable results over the last several decades. In recognition of those accomplishments, in June 2003 the 132nd session of the Executive Committee of the Pan American Health Organization (PAHO) called on the Member States of PAHO to prepare, within one year, national action plans for the elimination of rubella and congenital rubella syndrome (CRS) by the year 2010. During the Executive Committee discussions, praise was given for the sustained efforts of the countries of the Region in the struggle to eradicate measles. The Executive Committee discussions also reiterated the recommendation that the countries establish specific line items for immunization within their national budgets, in order to protect the investments in immunization that the Region's countries have made. The analysis of results of mass vaccination against rubella indicates that the benefits coming from accelerated control greatly exceed the costs associated with the treatment and rehabilitation of children with CRS. Various factors have created an environment that supports the goal of eliminating rubella and CRS from the Americas by the year 2010. These factors include the rapid reduction in morbidity that has come from the accelerated rubella control strategy; the availability of a safe, affordable, efficacious vaccine; the evidence of the cost benefit of vaccinating against rubella; and the broad support provided by the public and by health authorities in the Member States of PAHO. 